\title{
Edge chipping resistance of ceramics: Problems of test method
}

\author{
George A. GOGOTSI* \\ Pisarenko Institute for Problems of Strength, 2, Timiryazevskaya Str., 01014, Kiev, Ukraine
}

Received: July 21, 2013; Revised: October 15, 2013; Accepted: October 30, 2013

CThe Author(s) 2013. This article is published with open access at Springerlink.com

\begin{abstract}
An unconventional method for determining the fracture resistance of brittle materials is discussed. This method employs a conical indenter to chip the rectangular edge of the specimen. Particular features of the method are the use of small specimens and the evaluation of the resistance of materials to the nucleation, initiation and propagation of a crack. It is shown that this method is somewhat similar to the Hertzian fracture method and to the way that early man selected stones to make tools and weapons. Measured data of the fracture resistance of ceramics is presented. It is confirmed that if a ceramic material is similar to the model material of linear elastic fracture mechanics (LEFM), then those fracture resistance values are directly proportional to the critical stress intensity factors (baseline). For elastic and inelastic ceramics, R-lines characterizing the fracture resistance to crack growth are plotted. It is shown that proportionality lines (edge chipping resistance versus critical stress intensity factor) may be straight lines for ceramics with similar structure (such as Y-TZP and Mg-PSZ). The effect of rounding of the conical indenter tip $(10-800 \mu \mathrm{m})$ on chip scar shape is indicated. Other aspects in the fracture behavior of ceramics during edge chipping are also analyzed. The advantages and disadvantages of the method are discussed. Further studies in this mechanico-physical research area are suggested.
\end{abstract}

Keywords: mechanical characterization; micromechanics; indentation; phase transformation; edge fracture (EF) method

\section{Introduction}

Modern evaluations of the fracture resistance of ceramics are usually based on linear elastic fracture mechanics (LEFM) [1]. In these evaluations, it is assumed that the material is linear elastic and isotropic and may be inelastic only at the crack tip [2]. Such materials include aluminum oxide $\left(\mathrm{Al}_{2} \mathrm{O}_{3}\right)$, silicon nitride $\left(\mathrm{Si}_{3} \mathrm{~N}_{4}\right)$ and other ceramics. However, many materials differ in structure and are inelastic, which is

* Corresponding author.

E-mail: gogotsi@ipp.kiev.ua disregarded even in the relevant ASTM, CEN and ISO standards [3], though it would be more reasonable, for instance, to use elastic-plastic fracture mechanics [1] and $J$-integral as a fracture criterion [4] for the reliable evaluation of inelastic ceramics. A telling illustration is the expansive attempt made to create high-toughness ceramics of which the first was "ceramic steel" (Mg-PSZ) [5]. However, this lesson has not been learnt and the critical stress intensity factor $K_{\mathrm{Ic}}$ is still considered applicable to the evaluation of the fracture resistance of ceramics that differ in structure and mechanical behavior. This hinders the improvement of ceramics and affects the reliability of ceramic products 
in engineering and restorative medicine. A shortcoming of the conventional fracture toughness methods is the use of relatively large specimens, which may be much bigger than the samples that will be applied in dental and other products. Moreover, these methods do not involve the determination of the crack-growth resistance of materials - a characteristic that may play an important role in evaluating the performance of ceramic products. These problems may possibly be resolved with the edge-chipping method, which is currently far from being perfect. Therefore, it is reasonable to optimize this method and to improve the test data treatment procedure. This problem is discussed below.

\section{Energy-based evaluation of the fracture resistance of ceramics}

In the infancy of mankind (more than half a million years B.C. [6,7]), there was no need for any hypotheses or models to successfully select a more crack-resistant stone for making weapons and tools. Two stones were stricken against each other (equal energy was supplied to each of them) to choose the one that displayed less damage. In his classical study, which opened the road to the development of fracture mechanics, Griffith [8] analyzed the energy needed to fracture glass and proved that its capability of resisting fracture is characterized by the energy $\gamma_{\mathrm{s}}$ required to create new surfaces when a crack propagates.

At the National Physical Laboratory (United Kingdom) [9], early man's core stone was replaced by a specimen with a sharp rectangular edge, while the hammer stone with a standard Rockwell indenter ${ }^{1}$ for chipping this edge (Fig. 1(a)). It went, however, unnoticed that this is an attempt to experimentally solve a fracture problem somewhat similar to the classical Hertzian problem [11]. A test fixture with a movable microscope for precision edge chipping was created. The ratio of the fracture load $p_{\mathrm{f}}$ to the distance $d$ from the point of its application to the edge [12] (or the slope angle of $p_{\mathrm{f}}$ vs. $d$ curve [13]) was used as a fracture characteristic $(M)$. Since its

\footnotetext{
${ }^{1}$ In Ref. [9], the Rockwell indenter was chosen without justification, though a spherical tip with a radius of 200 $\mu \mathrm{m}$ is known to be minimum for elastic contact between the indentor and the material [10].
}

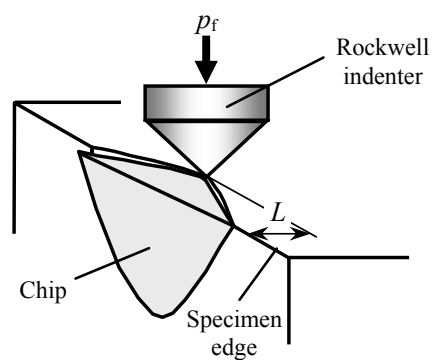

(a)

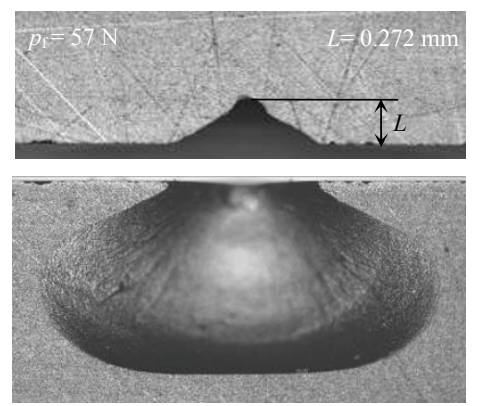

(b)

Fig. 1 (a) Schematic of edge-chipping method and

(b) chip scars of $\mathrm{La}_{0.8} \mathrm{Ca}_{0.2} \mathrm{CoO}_{3}$ perovskite ceramics.

unit is $\mathrm{N} / \mathrm{m}$, i.e., the same as the unit of fracture energy, this characteristic is named edge toughness. In Refs. [12] and [13], it is shown that for hard metals (and some other materials), this characteristic is in a nonlinear relationship with the critical strain energy release rate $G_{\text {Ic }}$ [1]. However, such a relationship is not observed for all brittle materials [14], probably because chip scars (and the corresponding fracture surfaces) on specimen edges can differ considerably among tested materials ${ }^{2}$ (Fig. 2). It should be noted that the edge-chipping method is the only method to determine the fracture resistance of brittle materials without the need to control the shape of fracture surfaces.

\section{Description of tests}

In the tests described in Ref. [15], a specimen bonded to a photographic glass was placed on the two-axis table of a CeramTest unit (Gobor Ltd.) mounted on a universal testing machine. To chip the edge, a standard diamond Rockwell indenter (Gilmore Diamond Tools, Inc.) with spherical tip of radius of $200 \mu \mathrm{m}$ fixed in the load rod of the test unit was used. The indentation

\footnotetext{
${ }^{2}$ In Ref. [9], however, it is stated that "flake geometries are remarkably similar and independent of the distance, force, or material."
} 


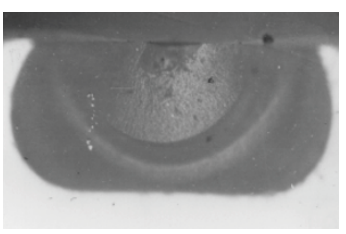

(a)

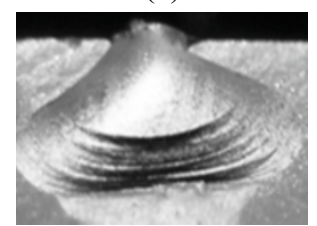

(c)

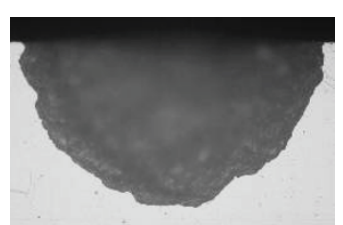

(b)

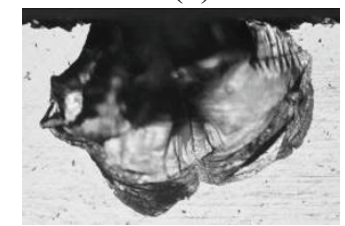

(d)
Fig. 2 Chip scars of (a) elastic Y-TZP and (b) inelastic Mg-PSZ zirconia ceramics as well as (c) silicon carbide EKasic ${ }^{\circledR} F$ ceramics and (d) polycrystalline silicon.

point was selected visually, with a magnifier. The indentation rate (crosshead speed) was constant and equal to $0.5 \mathrm{~mm} / \mathrm{min}$, as in standard tests on ceramics. During the tests, a computer recorded the time dependence of the displacement of the crosshead, which was stopped upon a decrease in the indenter load. The maximum load on the indenter is considered to be the fracture load $p_{\mathrm{f}}$ (Fig. 1). Then a BX51M Olympus (50-1000×) binocular microscope with QuickPhoroMicro 2.3 software was used to photograph the chip scars and to measure the distance (called fracture distance $L$ ) from the specimen edge to the extreme point of the chip scar (Fig. 1). These tests employed fragments of specimens that had been used to measure fracture toughness ( $K_{\text {Ic }}$ values [16]). A load support was installed in the CeramTest unit to provide free displacement of a specimen with a $\mathrm{V}$-shaped notch with a tip radius of no greater than $10 \mu \mathrm{m}$ (SEVNB method). The critical stress intensity factor $\left(K_{\mathrm{Ic}}\right)$ was determined using the following formula:

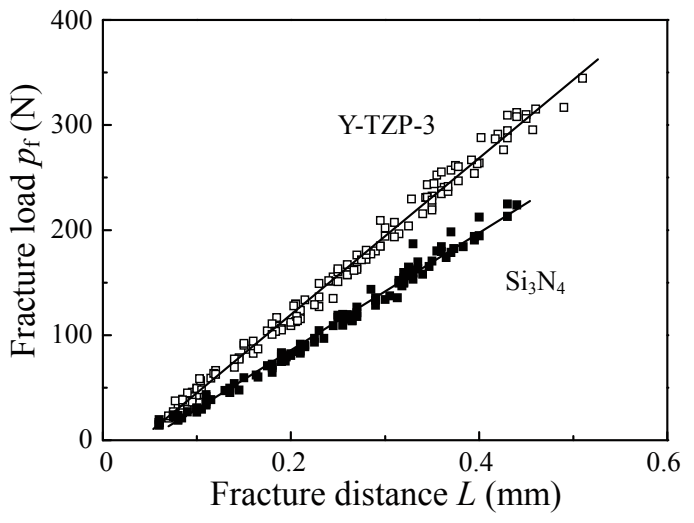

(a)

$$
K_{\mathrm{Ic}}=\frac{F}{B \sqrt{W}} \cdot \frac{S}{W} \cdot \frac{3 \sqrt{\alpha}}{2} \cdot Y^{*}
$$

where

$$
Y^{*}=\frac{1.99-\alpha(1-\alpha)\left(2.15-3.93 \alpha+2.7 \alpha^{2}\right)}{(1+2 \alpha)(1-\alpha)^{3 / 2}}
$$

$F$ is the fracture load; $B$ and $W$ are the width and height of the specimen, respectively; $S$ is the distance between the support rollers; $a$ and $\alpha=a / W$ are the absolute and relative depths of the notch, respectively.

The specimens were mirror-polished by $4 \mathrm{~mm} \times$ $3 \mathrm{~mm}$ rectangular beams with sharp edges rounded to a radius of no greater than 10-15 $\mu \mathrm{m}$. Fracture toughness and fracture resistance were measured on the same specimen to avoid any doubt that the materials tested under different conditions were different. Based on a great amount of statistically reliable test data, a method for edge fracture $(\mathrm{EF})$ tests with a Rockwell indenter was developed [15]. Its major feature is an original analysis of edge-chipping data and a mechanicophysical approach to the problem. Emphasis in the method is placed on the fact that dissimilar brittle materials have very different chip scars; therefore, their surfaces are photographed in the indentation and perpendicular directions for further examination. After the completion of tests, fracture diagrams $\left(p_{\mathrm{f}}\right.$ versus $L$ ) are plotted. They are linear for elastic materials and nonlinear for inelastic materials (Fig. 3). Fracture resistance value is calculated as follows [15]:

$$
F_{\mathrm{r}}=\frac{1}{n} \sum_{i=1}^{n} \frac{p_{\mathrm{f} i}}{L_{i}}
$$

where $p_{\mathrm{f} i}$ and $L_{i}$ are the current fracture load and fracture distance, respectively.

The collected statistically reliable test data were

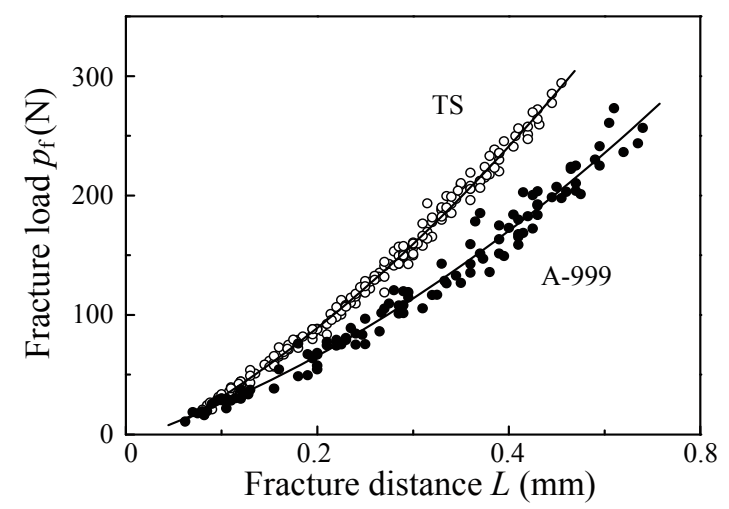

(b)

Fig. 3 Fracture diagrams of (a) elastic Y-TZP and silicon nitride $\mathrm{Si}_{3} \mathrm{~N}_{4}$ as well as (b) inelastic TS and alumina A-999 ceramics. 
used to compare fracture resistance, $F_{\mathrm{r}}$, and fracture toughness $K_{\mathrm{Ic}}$ values, determined on the same specimens of ordinary homogeneous single-phase ceramics similar in mechanical behavior to the LEFM model material. It appears that these quantities are in a linear relationship (Fig. 4), called the baseline [15]. This line indicates that the two essentially different test methods make equivalent assessments of fracture resistance. It can be used to determine how similar the tested ceramic material is to the LEFM model material and, hence, to validate the $K_{\mathrm{Ic}}$ values found by any LEFM-based test method. Therefore, it was proposed to add the EF method to the fracture toughness test standards for ceramics [17].

\section{Analysis of test data}

An analysis of the test data reveals that the relationship between edge-chipping fracture characteristic and fracture toughness is linear for ceramics with similar mechanical behavior (such as inelastic Mg-PSZ and elastic Y-TZP ceramics; Fig. 5). Direct proportionality (similar to the baseline) is also observed in tests with other indenters such as a Vickers indenter [18]. When plotted on the base diagram, such straight lines (which may be called proportionality lines) have a smaller slope angle than that of the baseline (Fig. 5) and therefore, they are less effective for comparison of tested ceramics.
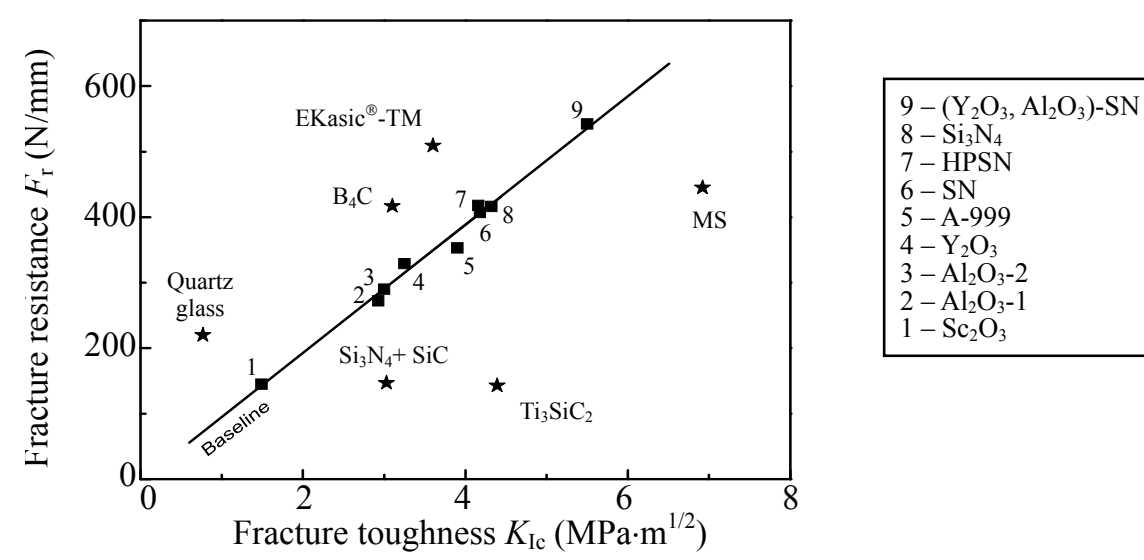

Fig. 4 Base diagram with baseline and data points for various ceramics and glasses.

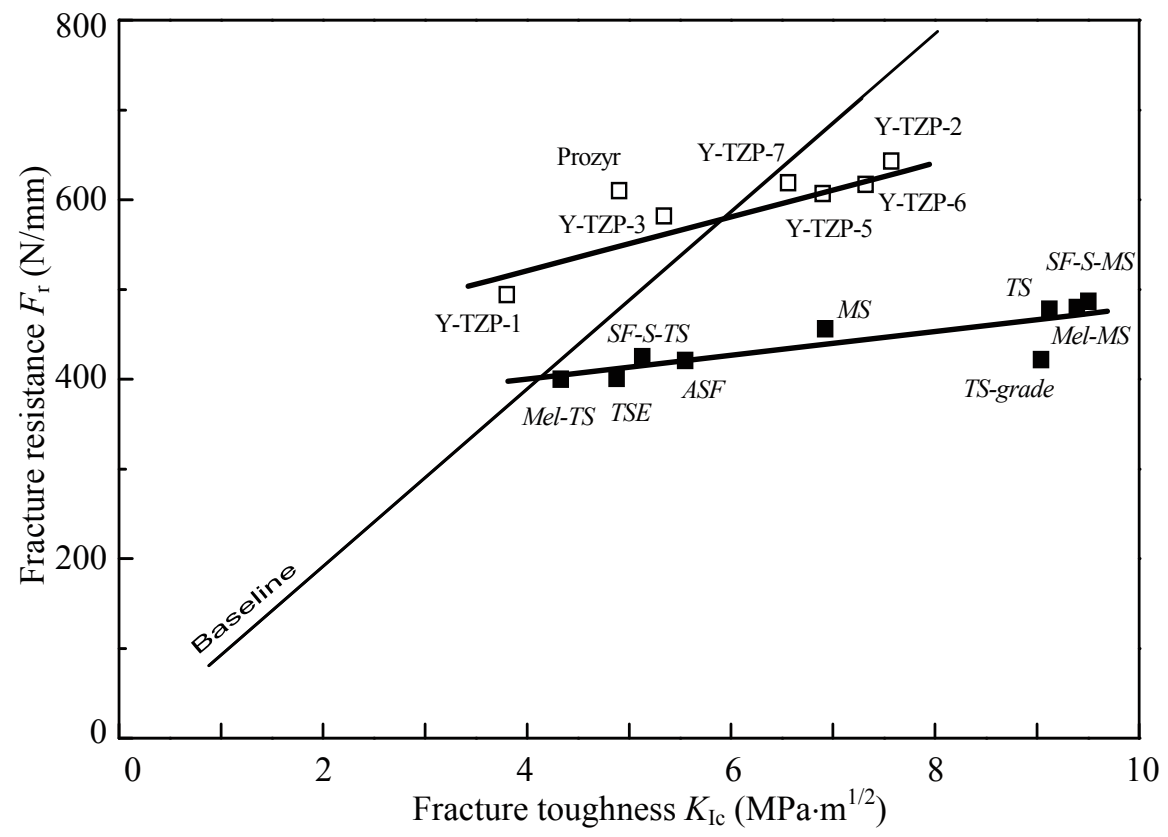

Fig. 5 Proportionality lines for elastic (Y-TZP) and inelastic (Mg-PSZ) zirconia ceramics. 
An analysis of the test data shows that both the fracture load and the surface area of the chip scar increase with the distance $L$. In Ref. [15], it was proposed to describe this effect by plotting fracture resistance $F_{\mathrm{r}}$ versus fracture distance $L$ (R-lines shown in Fig. 6). Note that R-lines are qualitatively similar to R-curves in LEFM [1]: in both cases, the fracture resistance of ceramics increases, which, in fact, corresponds to the increase in the area of the fracture surface (LEFM methods deal only with the length of the propagating crack). The correspondence of nonlinearly rising $\mathrm{R}$-line and R-curve was analyzed in Ref. [15], and it was established that the respective evaluations of the fracture resistance of ceramics are similar. This is important because the R-line is obtained from small specimens tested with relatively simple test equipment. Contrastingly, plotting the R-curve is quite difficult and possible only in a specialized mechanical laboratory.

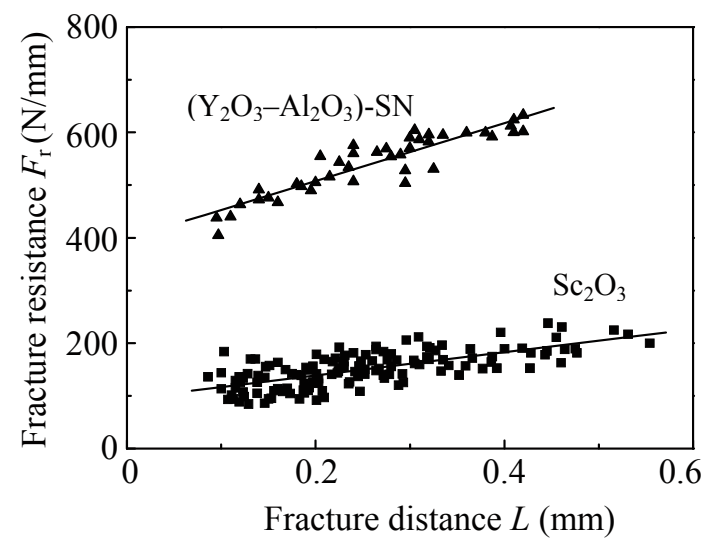

(a)

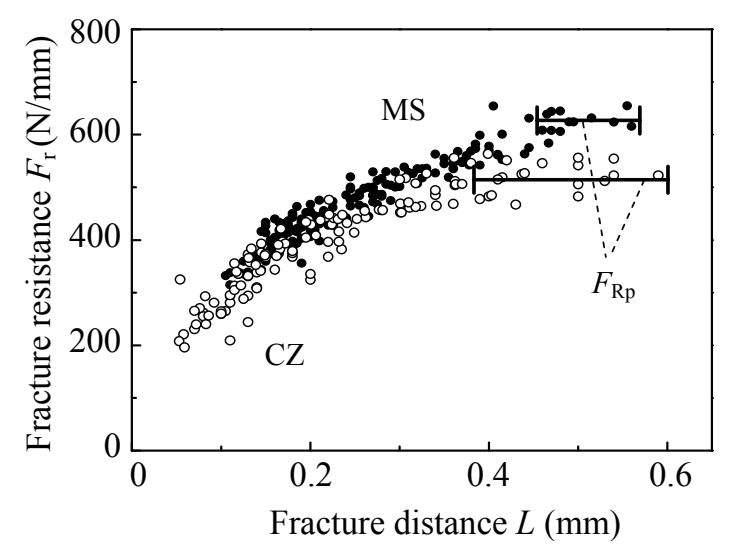

(b)

Fig. 6 R-lines of (a) elastic silicon nitride $\left(\mathrm{Y}_{2} \mathrm{O}_{3}-\mathrm{Al}_{2} \mathrm{O}_{3}\right)-\mathrm{SN}$ and scandia oxide $\mathrm{Sc}_{2} \mathrm{O}_{3}$ ceramics, and (b) inelastic zirconia $\mathrm{MS}$ and composites alumina+zirconia $\mathrm{CZ}$ ceramics.
Summing up the aforementioned, it should be pointed out that the EF method is promising for the comparative fracture resistance evaluations of ceramics with similar chip scars and for the study of their fracture resistance. In this case, not only R-lines are plotted and $F_{\mathrm{r}}$ is determined, but also a new fracture characteristic $F_{\mathrm{Rp}}$ of ceramics corresponding to the plateau of R-lines (Fig. 6(b)) [17] can be determined. Note that a similar characteristic was proposed earlier in analyzing an R-curve [19], but it was not accepted probably because of the technical difficulties of obtaining it, which is not so when using the EF method. This characteristic may be of practical interest. It should also be pointed out that all methods for determining the edge chipping resistance of ceramics (as well as ordinary LEFM methods), unlike the prehistoric method, are actually unsuitable for the reliable evaluation of dissimilar ceramics and other brittle materials, i.e., are not "universal" methods.

In studying the fracture of materials with the method in question, it is possible, following Ref. [20], to examine a chip scar on a quartz glass specimen (Fig. 7) made with a Rockwell indenter (spherical tip). At the first stage of fracture, tensile stresses cause a microdefect that is always present on the surface to grow to a critical size, thus nucleating a crack, which is a critical event leading to fracture [21]. At the second stage of fracture, an incipient surface crack (a part of a ring crack) develops ${ }^{3}$. The third stage is the initiation and propagation of a pseudo-conical crack. This pattern is somewhat similar to the formation of a Hertzian cone crack [12], which is studied using compound specimens (two pieces glued together) separated after the test [24] to examine the fracture surfaces.

It should be noted that the second stage of fracture is controlled by the properties of the subsurface layer, which is, unfortunately, disregarded. Therefore, the most complicated is the second stage of fracture, which corresponds to the fracture onset barrier [25], typical for the materials under consideration. In Ref. [15], it was shown that brittle materials may have barriers of three types. A low fracture barrier (mentioned in Ref. [26] with reference to inelastic and composite ceramics)

\footnotetext{
3 At large values of $L$, not only parts of a ring crack, but also radial cracks may propagate because the stress-strain state in the contact region between the indenter and the specimen becomes symmetric [22] (Hertzian problem [11]). This is disregarded in Ref. [23].
} 


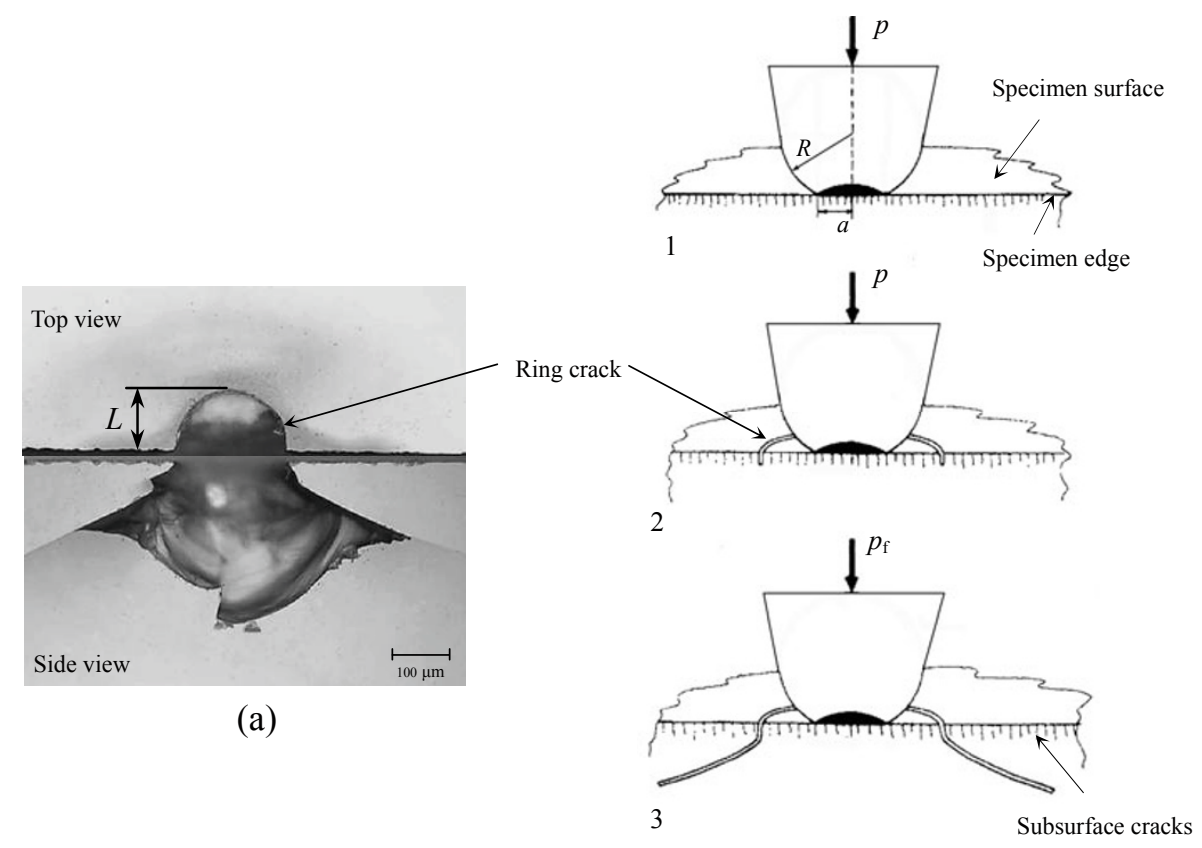

(b)

Fig. 7 (a) Chip scar on quartz glass specimen and (b) fracture development scheme: 1, 2 and 3 denote stages of fracture; $R$ is the indenter tip radius; $a$ is the radius of the contact area between the indenter and the specimen.

is observed when data points lie below the baseline (Figs. 4 and 5). It was established that it is due to the presence of microcracks, weak bonds between grains, phase transitions, and other effects in the subsurface layer. Contrastingly, the "normal" fracture barrier does not affect fracture resistance (it is typical for ceramics with data points on the baseline). Of interest is a high fracture barrier observed in glass and in ceramics used to manufacture cutting tools and armor: data points lie above the baseline (Fig. 4). Its cause is unclear. It is only known [15] that the fracture zones caused by an indenter in such materials are very different from those in materials with data points on the baseline (Fig. 8). This is indicative of the fact, known in contact mechanics, that each material resists local fracture in its own way, which was earlier disregarded. An attempt was made in Ref. [18] to analyze a high fracture barrier based on edge-chipping data obtained with a Vickers indenter, which causes elastic-plastic fracture of the material. In this case, however, the concept of fracture onset barrier loses its meaning. At the beginning of our studies, following Ref. [27], we also tried to understand this effect by scratching the specimen with a Rockwell indenter until chipping [28]. Actually, that is meaningless because a scratch not only partially excludes the first stage of fracture, but also forms an additional uncontrollable stress concentrator that depends on the material and the load applied to the indenter. Thus, the high fracture onset barrier in ceramics is yet to be evaluated and understood, and it is still unclear whether the descriptions of the edge-chipping fracture of many brittle materials are reliable. This is one of the important reasons why edge-chipping data cannot often be used to compare the fracture resistance of different brittle materials. A shortcoming of ordinary edge-chipping tests is the use of a relatively sharp Rockwell indenter, which causes both quasi-cone chip scars (elastic fracture) and scalloplike chip scars (elastic-plastic fracture) on fused quartz specimens [29]. This is why the fracture resistance of this material may be assigned different values. The problem can be resolved with an indenter with a tip radius of $400 \mu \mathrm{m}$ (Fig. 9). Therefore, conical diamond indenters with different tip radii (Gilmore Diamond Tools, Inc., USA) were used in edge chipping of soda lime glass (often considered as a model material). It was established that an indenter with a tip radius of $10 \mu \mathrm{m}$ does not produce pseudo-conical chip scars on glass specimens. There are $38 \%$ of such scars if the tip radius is $100 \mu \mathrm{m}, 68 \%$ if it is $200 \mu \mathrm{m}$, and $100 \%$ if it is $400 \mu \mathrm{m}$. An $800-\mu \mathrm{m}$ indenter leaves only pseudo-conical scars. It was noticed that a steel indenter with a tip radius of $2000 \mu \mathrm{m}$ makes a chip scar of different shape on the edge of Y-TZP ceramics specimens (see Figs. 2 and 10). 


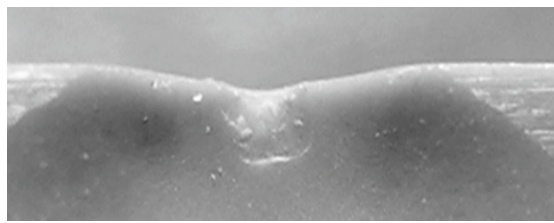

(a)

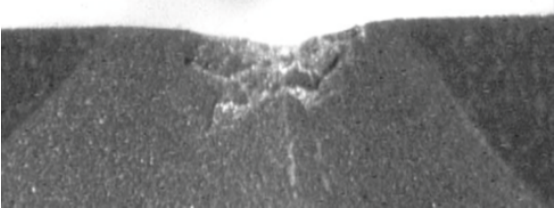

(b)

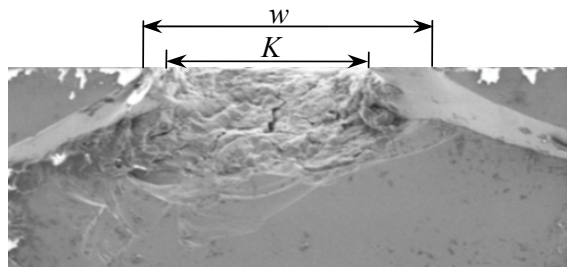

(c)

Fig. 8 (a) Chip scar of silicon nitride GPSSN ceramics with data points on the baseline and (b) chip scars of silicon carbide EKasic ${ }^{\circledR}$ TM ceramics and (c) light crown glass whose data points are above the baseline: $K$ is the width of the zone damaged by the indenter and $w$ is the chip scar size in the indentation direction.

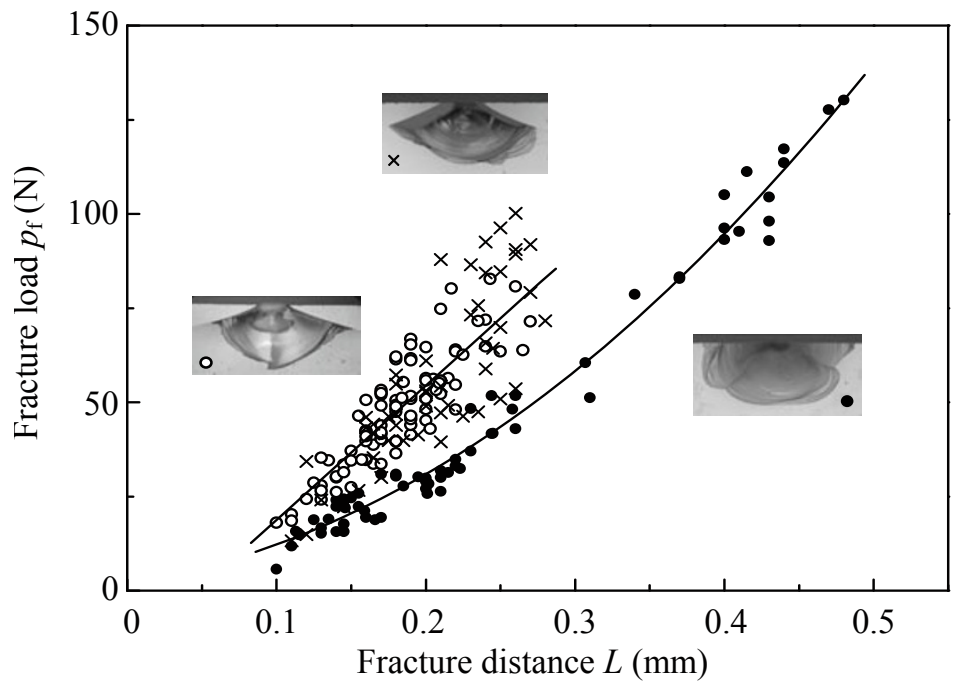

Fig. 9 Fracture diagrams of fused silica: data points for quasi-cone chip scars $((\bigcirc)$ Rockwell and $(\times)$ conical indenters) and for scallop-like chip scars ((O) Rockwell indenter).

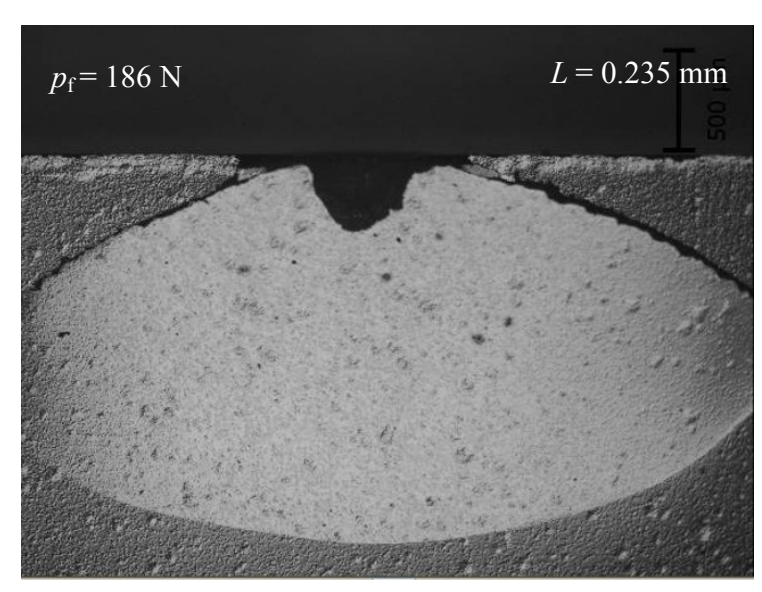

Fig. 10 Chip scar on Y-TZP ceramics (indenter tip radius of $2000 \mu \mathrm{m})$.

\section{Conclusions}

The edge-chipping method (with Rockwell indenter) is still a long way from perfection and can successfully be used only for the comparative evaluations of the fracture resistance of brittle materials that show similar local fracture behavior. Important tasks for subsequent research is to find the optimal radius of the indenter tip and to study the fracture behavior of the surface and subsurface layer of specimens to improve the reliability of evaluations of the fracture resistance of brittle materials made by this method.

\section{Acknowledgements}

The author is grateful to V. Galenko for technical assistance.

Open Access: This article is distributed under the terms of the Creative Commons Attribution License which permits any use, distribution, and reproduction in any medium, provided the original author(s) and the source are credited. 


\section{References}

[1] Broek D. Elementary Engineering Fracture Mechanics. Dordrecht: Kluwer Academic Publishers, 1986.

[2] Irwin GR. Analysis of stresses and strains near the end of a crack traversing a plate. J Appl Mech 1957, 24: 361-364.

[3] ISO 23146:2008. Fine ceramics (advanced ceramics, advanced technical ceramics)-Test methods for fracture toughness of monolithic ceramicsSingle-edge V-notch beam (SEVNB) method. Gevena: ISO, 2008.

[4] Evans AG, Faber KT. Crack-growth resistance of microcracking brittle materials. J Am Ceram Soc 1984, 67: 255-260.

[5] Garvie RC, Hannink RH, Pascoe RT. Ceramic steel? Nature 1957, 258: 703-704.

[6] Brumm A, Aziz F, van den Bergh GD, et al. Early stone technology on Flores and its implications for Homo floresiensis. Nature 2006, 441: 624-628.

[7] Balter M. New light on revolutions that weren't. Science 2012, 336: 530-531.

[8] Griffith A. The phenomena of rupture and flow in solids. Phil Trans R Soc Lond A 1921, 221: 163-198.

[9] Almond EA, McCormick NJ. Constant-geometry edge-flaking of brittle materials. Nature 1986, 321: 53-55.

[10] Evans AG, Wilshaw TR. Quasi-static solid particle damage in brittle solids-I. Observations analysis and implications. Acta Metall 1976, 24: 939-956.

[11] Fischer-Cripps AC. Introduction to Contact Mechanics, 2nd edn. New York: Springer, 2007.

[12] McCormick NJ, Almond EA. Edge flaking of brittle materials. J Hard Mater 1990, 1: 25-51.

[13] Morrell R, Gant AJ. Edge chipping of hard materials. Int $J$ Refract Met H 2001, 19: 293-301.

[14] Gogotsi GA, Galenko VI, Mudrik SP, et al. Fracture resistance estimation of elastic ceramics in edge flaking: EF baseline. J Eur Ceram Soc 2010, 30: 1223-1228.

[15] Gogotsi GA. Fracture resistance of ceramics: Base diagram and $R$-line. Strength Mater 2006, 38: 261-270.
[16] Gogotsi GA. Fracture toughness of ceramics and ceramic composites. Ceram Int 2003, 29: 777-784.

[17] Gogotsi GA. Criteria of ceramics fracture (edge chipping and fracture toughness tests). Ceram Int 2013, 39: 3293-3300.

[18] Gogotsi GA, Mudrik SP. Fracture barrier estimation by the edge fracture test method. Ceram Int 2009, 35 : 1871-1875.

[19] Readey MJ, Heuer AH, Steinbrech RW. Crack propagation in Mg-PSZ. MRS Proc 1986, 78: 107-120.

[20] Wilshaw TR. The Hertzian fracture test. J Phys D: Appl Phys 1971, 4: 1567-1581.

[21] Knott JF. Micromechanisms of fracture and the fracture toughness of engineering alloys. In Fracture. Taplin DMR, Ed. Canada: University of Waterloo Press, 1977: 61-92.

[22] Batanova OA, Gogotsi GA, Matvienko YuG. Numerical analysis of edge chipping data. Ind Lab Diag Mater 2011, 77: 53-56. (in Russian)

[23] Chai H. On the mechanics of edge chipping from spherical indentation. Int $J$ Fracture 2011, 169: 85-95.

[24] Guiberteau F, Padture NP, Lawn BR. Effect of grain size on Hertzian contact damage in alumina. $J \mathrm{Am}$ Ceram Soc 1994, 77: 1825-1831.

[25] Drucker DC. Macroscopic fundamentals in brittle fracture. In Treatise on Fracture. Liebowitz H, Ed. New York: Academic Press, 1968: 473-531.

[26] Gogotsi GA. The problem of the classification of low-deformation materials based on the features of their behavior under load. Strength Mater 1977, 9: 77-83.

[27] Quinn J, Su L, Flanders L, et al. "Edge toughness" and material properties related to the machining of dental ceramics. Mach Sci Technol 2000, 4: 291-304.

[28] Gogotsi GA, Mudrik SP, Quinn J. Edge toughness of silicon nitride ceramics: Method and results. In Proceedings of the International Conference on Novel Technologies in Power Metallurgy and Ceramics. Kiev: IPMS, 2003: 375-376.

[29] Gogotsi GA, Mudrik SP. Glasses: New approach to fracture behavior analysis. J Non-Cryst Solids 2010, 356: 1021-1026. 